\author{
Review Article \\ www.ijrap.net
}

\title{
BENZIMIDAZOLE: AN OVERVIEW
}

Rituparna Palit ${ }^{1 *}$, Rajesh Kumar ${ }^{2}$, Nikita Saraswat ${ }^{1}$, Ankita Wal ${ }^{3}$, Prabhat Kumar Upadhyaya ${ }^{4}$

${ }^{1}$ Assistant Professor, Department of Pharmacy, Pranveer Singh Institute of Technology, Kanpur, U.P, India

${ }^{2}$ Student, Department of Pharmacy, Shri Ram MurtiSmarak College of Engineering and Technology, Bareilly, U.P, India

${ }^{3}$ Associate Professor, Department of Pharmacy, Pranveer Singh Institute of Technology, Kanpur, U.P, India

${ }^{4}$ Assistant Professor, Institute of Pharmaceutical Research, GLA University, Mathura, U.P., India

Received on: 04/10/16 Revised on: 15/11/16 Accepted on: 02/12/16

*Corresponding author

E-mail: rituparna.palit32@gmail.com

DOI: 10.7897/2277-4343.076243

\section{ABSTRACT}

Benzimidazole derivatives are versatile nitrogen containing heterocyclic compounds which have long been known as a promising class of biologically active compounds possessing wide variety of biological and pharmacological activities like antibacterial, anti-inflammatory, anti-ulcer, anti-diabetic etc. Scientists have elucidated that Benzimidazole system possesses the variable sites like position 2 and 5 which can be suitably modified to yield potent therapeutic agents. The present review covers the chemistry and pharmacological activities of substituted bezimidazoles.

Keywords: Benzimidazole, anti-fungal, anti-histaminic, anti-convulsant, anti-inflammatory, analgesic, anti-viral, anti-oxidant, anti-cancer and antiulcerative.

\section{INTRODUCTION}

Benzimidazole is as aromatic heterocyclic organic compound. The synthesis of benzimidazole based polyheterocycles draw the attention of pharmacists from last few decades as it functions as an important pharmacophore in medicinal chemistry and pharmacology. Basically, benzimidazole is a bicyclic compound consisting of the fusion of benzene with imidazole which ultimately gives a privileged structure. This magical moiety possesses many pharmacological properties. Till now the most prominent benzimidazolemoiety is $N$-ribosyldimethylbenzimidazole present in nature and it serves as the axial ligand for cobalt in vitamin $\mathrm{B}_{12}{ }^{1}$<smiles>c1ccc2[nH]cnc2c1</smiles>

\section{Benzimidazole}

Benzimidazolepossess many biological activities such as antimicrobial, anti-fungal, anti-histaminic, anti-inflammatory, antiviral, anti-oxidant, anti-cancer, anti-ulcerative etc., that's why benzimidazole derivatives are considered as an important moiety for the development of molecules of pharmaceutical interest. ${ }^{2,3}$

There is biological relevance of many heterocyclic building blocks is due to the structural similarity to purine nucleobase and as benzimidazole derivative also which selectively inhibits the endothelial cell growth and then suppresses the process of angiogenesis in vitro as well as in vivo. ${ }^{3}$

In addition to this activity, substituted benzimidazoles plays the role of potent inhibitors of parietal cell $\mathrm{H}^{+} / \mathrm{K}^{+}$ATPase (proton pump).
Moreover, a benzimidazole when substituted with proline bisamide, it is helpful in curing insomnia and promotes sleep; it acts as a potent orexin inhibitor which was found from high throughput screening. Orexins plays a wide range of functions in CNS which includes regulation of normal sleep-wake cycle and feeding behaviors. Patients of narcolepsy have seen with a disfunctioning of neurons responsible for orexin production. ${ }^{5}$

Benzimidazoles when substituted with aminothio carbamoyl hydrazine carbonyl, 1,3,4-thiadiazole and $4 \mathrm{H}-1,2,4$-triazole at $1^{\text {st }}$ position via a methyl chain and the $2^{\text {nd }}$ position is substituted with phenyl, $p$-chlorophenyl, $p$-methoxyphenyl and pyridinyl rings then the derivatives of benzimidazolemoiety shows potent antioxidant properties. ${ }^{6}$

The planar chromophoric ability of benzoannulatedbenzimidazole such as benzimidazo [1,2a]quinolines or benzimidazo[1,2-a]quinazolines have the ability to get inserted between adjacent base pairs of DNA molecule in the intercalation process and also they can be used as fluorescent probes in assays(homogeneous) of biological molecules. ${ }^{7}$

Some reports suggested that benzimidazoles substituted with hydrogen at $1^{\text {st }}$ position were found active against E.histolytica. ${ }^{8}$

\section{PHARMACOLOGICAL ACTIVITIES Anti-inflammatory activity}

Suresh et al., (2011) synthesized derivatives having thiophene nuclei bind with benzimidazole moiety $\mathbf{1}$. Newly synthesized compounds were then screened for anti-inflammatory activity and showed significant effect when compared with standard Diclofenac sodium. ${ }^{9}$ 
<smiles>[R]C1C(=O)CSC1c1nc2ccccc2[nH]1</smiles>

$\mathrm{R}=$ cinnamaldehyde, $\mathrm{m}$-nitrobenzaldehyde, $\mathrm{m}$-methoxy benzaldehyde

Thakurdesai et al., (2007) synthesized benzimidazole-2carboxylic acid derivatives $\mathbf{2}$. They were tested for acute antiinflammatory activity and found to be potent anti-inflammatory agent. $^{10}$

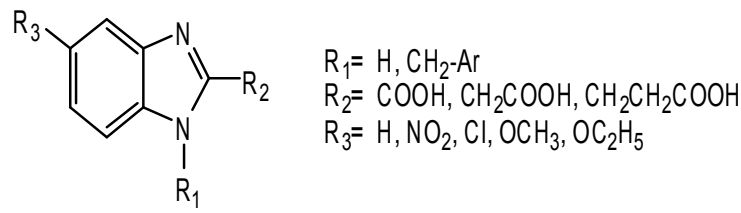

(2)

Babu et al., (2010) synthesized novel $N$-(1H-Benzimidazol-2yl)-2-Isatinylidene-Hydrazinecarboxamide Derivatives 3. These agents were then evaluated for anti-inflammatory effect and found to be potent. ${ }^{11}$

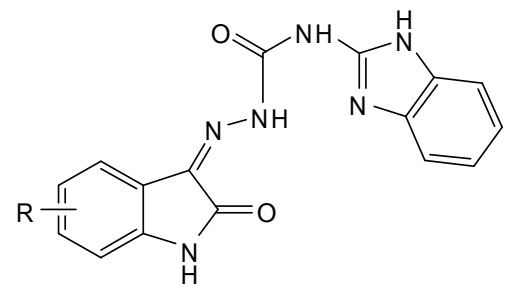

$\mathrm{R}=5-\mathrm{CH}_{3}, 5-\mathrm{NO}_{2}, 7-\mathrm{COOH}, 7-\mathrm{Br}, 7-\mathrm{Cl}$

(3)

Achar et al., (2010) have synthesized a series of 2methylaminobenzimidazole derivatives 4 . The newly synthesized compounds were screened for analgesic and anti-inflammatory activities. Compounds 2 and 7 showed a potent analgesic $(89 \%$ at $100 \mathrm{mg} / \mathrm{kg}$ b.w.) and anti-inflammatory (100\% at $100 \mathrm{mg} / \mathrm{kg}$ b.w.) activities. ${ }^{12}$

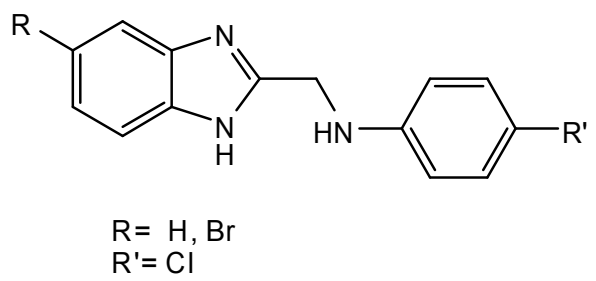

(4)

Gaba et al., (2010) synthesized a series ofnovel 5-substituted-1(phenylsulfonyl)-2-methylbenzimidazole derivatives5. These compounds were screened for anti-inflammatory and analgesic activity as well as gastric ulcerogenic effects. These derivatives showed good activity. ${ }^{13}$<smiles>[R]Nc1ccc2c(c1)nc(C)n2S(=O)(=O)c1ccccc1</smiles>

$$
\begin{aligned}
& \mathrm{a}=p-\mathrm{NH}_{2} \mathrm{C}_{6} \mathrm{H}_{4} \\
& \mathrm{~b}=0-\mathrm{NH}_{2} \mathrm{C}_{6} \mathrm{H}_{4}
\end{aligned}
$$$$
c=p \cdot \mathrm{NH}_{2} \mathrm{C}_{7} \mathrm{H}_{6}
$$

(5)

Mariappan et al., (2011) have synthesized a new series of [1 ( $N$-substituted amino) methyl]-2-ethyl benzimidazole derivatives6. These derivatives were screened for analgesic and anti-inflammatory activity. These derivatives were showed excellent activity. ${ }^{14}$<smiles></smiles>

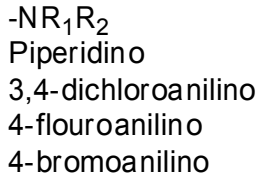

(6)

Jesudason et al., (2009) have synthesized a novel series of $N$ Mannich bases of benzimidazole derivatives7. These compounds were screened for analgesic, anti-inflammatory and in-vitro bovine corneal permeability activities. Compounds 7 was found to have potent activity. ${ }^{15}$<smiles>[R2]Cn1c([R])nc2ccccc21</smiles>

$$
\begin{aligned}
& \mathrm{R}_{1}=-\mathrm{CH}=\mathrm{CHC}_{6} \mathrm{H}_{5} \\
& \mathrm{R}_{2}=-\mathrm{N}\left(\mathrm{C}_{2} \mathrm{H}_{5}\right)_{2},-\mathrm{NC}_{5} \mathrm{H}_{5}
\end{aligned}
$$

Shanmugapandiyan et al., (2010) synthesized A new series of 2-[4-(azetidin-2-one)-3-chloro-4-phenyl]- $1 H$ -

Phenylbenzimidazole and 2-(thiazolidin-4-one)-phenyl- $1 \mathrm{H}$ Phenylbenzimidazole8. These derivatives were screened for antibacterial and anti-inflammatory activity. Compounds $8_{1}$ and 83 were showed good analgesic and anti-inflammatory activity. ${ }^{16}$ 


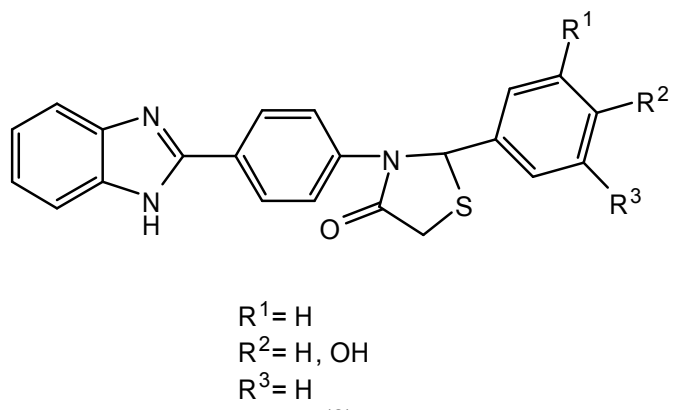

(8)

Reddy (2010) has synthesized 1,2-disubstituted benzimidazole derivatives9. These derivatives were screened for antiinflammatory activity. Compound showed potent activity. ${ }^{17}$<smiles>NC(c1ccccc1)c1nc2ccccc2[nH]1</smiles>

(9)

Leonard et al., (2006) have synthesized some new Phenyl benzimidazole derivatives10. These derivatives were screened for anti-inflammatory activity. The compound $1 \mathrm{c}$ was showed maximum (54.6\%) inhibition of edema at doses of $50 \mathrm{mg} / \mathrm{kg} .{ }^{18}$<smiles>[R1]CN1c2ccccc2NC1c1cccc([R1])c1</smiles>

(1c; $\mathrm{R}=$ dimeth ylamine, $\mathrm{R}_{1}=\mathrm{Cl}$ )

(10)

Gaud et al., (2011) have synthesized a new series of substituted benzimidazole derivatives11. These compounds were screened for analgesic and anti-inflammatory activities by biological evaluation method and also for other possible pharmacological activities including antibacterial activity. These derivatives were showed potent analgesic and anti-inflammatory activity. ${ }^{19}$

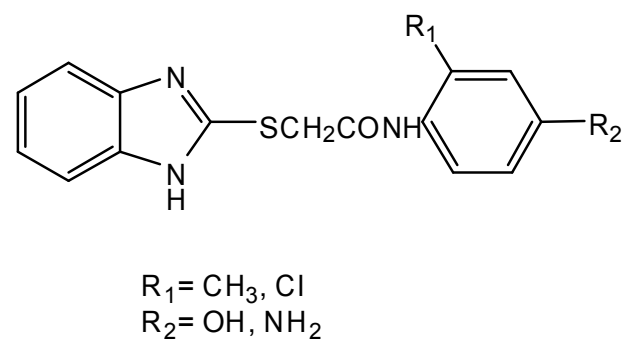

(11)

Sondhi et al., (2002) have synthesized some novel pyrimido[1,6-a]benzimidazole derivatives12. These derivatives were screened for anti-inflammatory, analgesic and antiamoebic activity. Compound $\mathbf{1 2 c}$ was showed good activity. ${ }^{20}$<smiles>[R2][R20]=N[O+]=[N+]([O-])[O-]</smiles>

(12)

Mohamed et al., (2006) have synthesized some new derivatives of 1,2,4-triazolo[2,3-a]benzimidazoles13. These derivatives were screened for antifungal, analgesic and anti-inflammatory activity. The compound $\mathbf{1 3 d}$ was found to be most potent. ${ }^{21}$

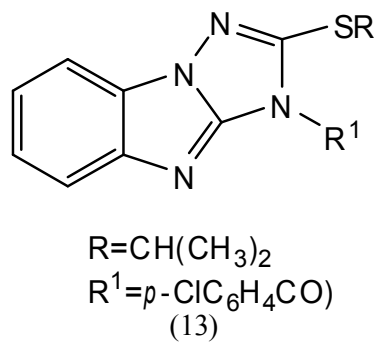

\section{Analgesic activity}

Kaplancikli et al., (2008) synthesized 1[(Benzoxazole/benzimidazole-2-yl)thioacetyl]pyrazoline derivatives $\mathbf{1 4}$ which then screened for analgesic activity and the synthesized compounds were found to be potent. ${ }^{22}$

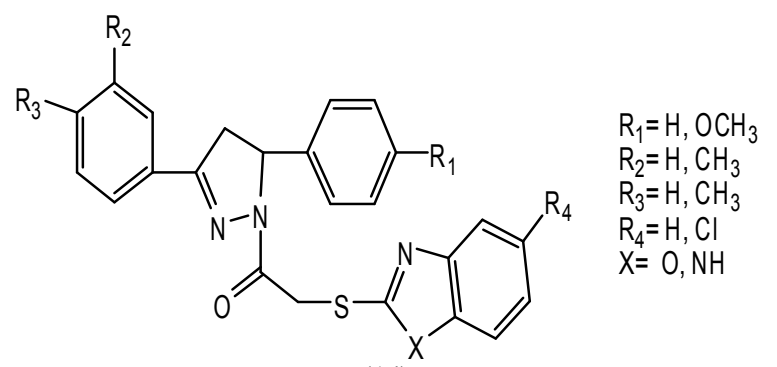

(14)

Shukla A. (2012) synthesized benzimidazoles derivative involves subsequent synthesis of 4-(2-chloro-ethoxy)benzaldehyde, 4-methyl benzaldehyde followed by benzimidazoles derivative $\mathbf{1 5}$. The synthesized benzimidazole compounds were screened for analgesic and anticonvulsant activity and some compounds showed significant analgesic activities. $^{23}$

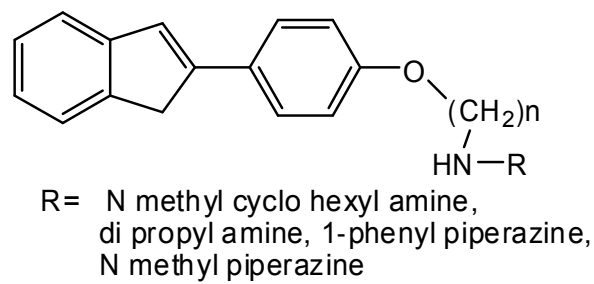

(15) 


\section{Anti-convulsant activity}

Singh et al., (2010) synthesized a series of 1, 2, 5-trisubstituted benzimidazoles derivatives 16a-c. The compounds with optimum chain length at position two $\left(\mathrm{R}_{2}\right)$ and electron withdrawing group at position five $\left(\mathrm{R}_{3}\right)$ showed better anticonvulsant activity. ${ }^{24}$

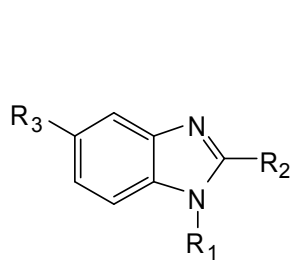

$$
\begin{aligned}
& \text { (a) } \\
& \mathrm{R}_{1}=1 \text {-picoline } \\
& \mathrm{R}_{2}=\mathrm{H}, \mathrm{CH}_{3}, \mathrm{C}_{2} \mathrm{H}_{5}, \mathrm{C}_{3} \mathrm{H}_{7} \\
& \mathrm{R}_{3}=\mathrm{H}, \mathrm{NO}_{2}
\end{aligned}
$$

(b)
$\mathrm{R}_{1}=2$-picoline
$\mathrm{R}_{2}=\mathrm{H}, \mathrm{CH}_{3}, \mathrm{C}_{2}$

$\mathrm{R}_{2}=\mathrm{H}, \mathrm{CH}_{3}, \mathrm{C}_{2} \mathrm{H}_{5}, \mathrm{C}_{3} \mathrm{H}_{7}$
$\mathrm{R}_{3}=\mathrm{H}, \mathrm{NO}_{2}$

(c)

$\mathrm{R}_{1}=3$-picoline

$\mathrm{R}_{2}=\mathrm{H}, \mathrm{CH}_{3}, \mathrm{C}_{2} \mathrm{H}_{5}, \mathrm{C}_{3} \mathrm{H}_{7}$

(16)

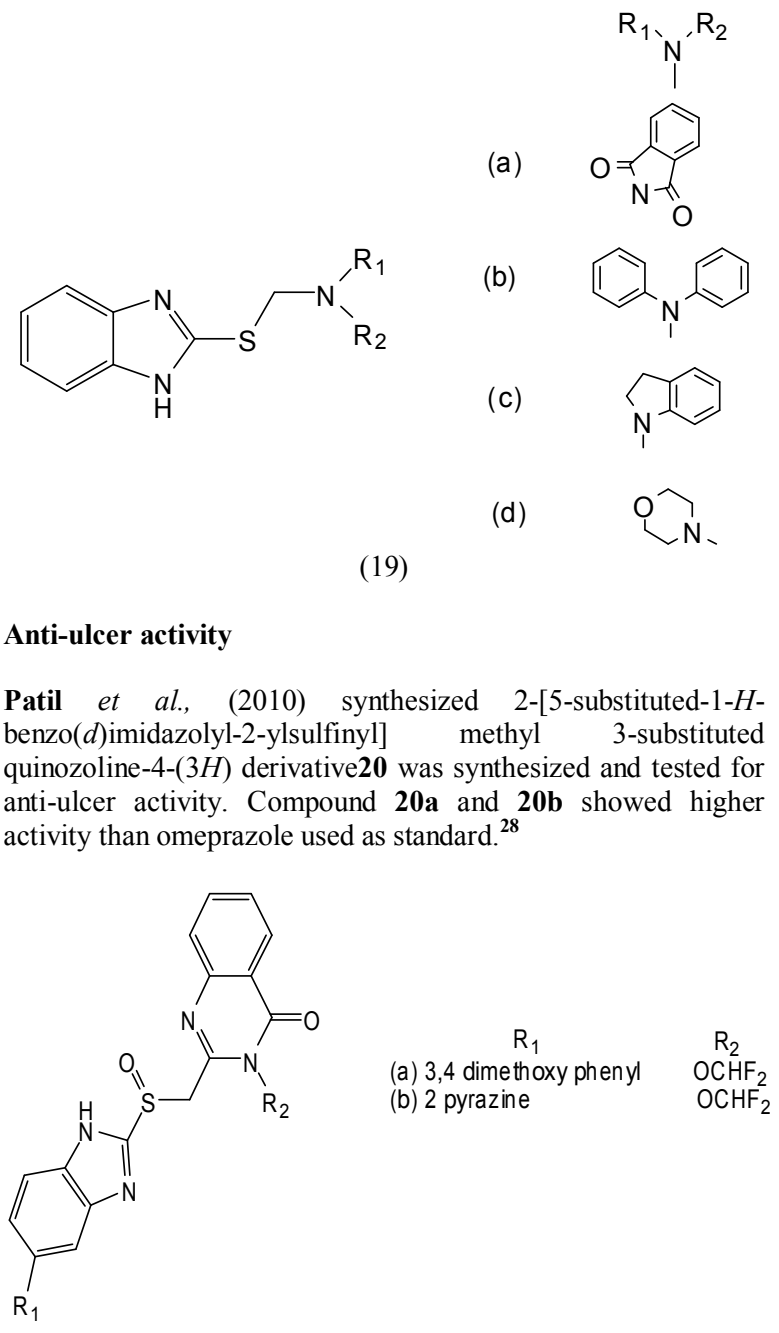

(20)

Nadeem and Khan (2011) studied to investigate the effect of 2(pyrimidinylsulfinyl) benzimidazole derivative $\mathbf{2 1}$ and the compound was found to have good antiulcer activity. ${ }^{29}$<smiles>[R]c1ccc2[nH]c(S(=O)(=O)c3cc([R])nc(C)n3)nc2c1</smiles>

2-[(2-methyl, 6- alkyl pyrimidin-4-yl)sulfinyl]-5-alkyl-1-H- benzimidazole

(21)

Thakare and Asnani (2011) synthesized a series of all new substituted 2-(pyrimidinylsulfinyl) benzimidazole22. All compounds were tested for antiulcer and anti-secretary activity and found to be potent. ${ }^{30}$
Anandarajagopal et al., (2010) synthesized a series of 2 mercaptobenzimidazole derivatives 19. Anticonvulsant activity was evaluated for newly synthesized derivatives. Most of the synthesized compounds exhibited anticonvulsant activity. ${ }^{27}$ 


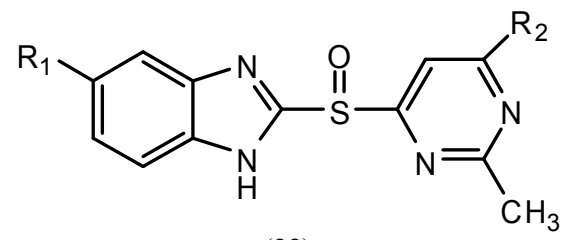

(22)

Shin et al., (2009) synthesized new aryl sulfonyl proton pump inhibitor (PPI) 23 prodrug forms. These prodrugs provided longer residence time of an effective PPI plasma concentration, resulting in better gastric acid inhibition. ${ }^{31}$
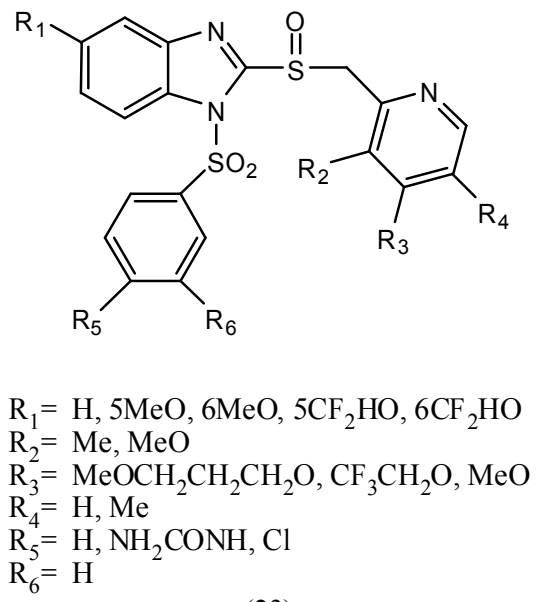

\section{CONCLUSION}

The review has concluded with the key pharmacological activities of the Benzimidazole. This moiety has shown a wide range of therapeutic value. This paper comprises of the major pharmacological activities ${ }^{32}$ of Benzimidazole and it can be used for further researches. Substituted benzimidazole moiety (specially at the $2^{\text {nd }}$ position) are reported to possess a number of interesting biological activities such as anti-inflammatory, analgesic, anti-convulsant and anti-ulcer activity. ${ }^{33}$

\section{REFERENCES}

1. Walia, R, Md. Hedaitullah, Naaz, SF, Iqbal, K and Lamba, HS. Benzimidazole Derivatives: An overview. International Journal of Research in Pharmacy and Chemistry 2011;1, Suppl 3: 565-574.

2. Yu Luo, Jia-Ping Yao, Li Yang, Chun-Lan Feng, Wei Tang, Gui-Feng Wang, Jian-Pin Zuo, and Wei Lu. Synthesis and Anti-Hepatitis B Virus Activity of a Novel Class of Thiazolylbenzimidazole Derivatives. Arch. Pharm. Chem. Life Sci. 2011; 2: 78-83.

3. Farukh A and Mubashira A.Synthesis and characterization of dinuclear macrocyclic cobalt(II), copper(II) and zinc(II) complexes derived from 2,2,2, $2^{\prime}-\mathrm{S}, \mathrm{S}$ [bis(bis-N,N2thiobenzimidazolyloxalato-1,2-ethane)]: DNA binding and cleavage studies.European Journal of Medicinal Chemistry 2009; 44: 834-844.

4. Dubey PK, Kumar NDM, Chaitanya MVSRK, Naidu A and Vineel G. Synthesis of novel benzimidazole $\beta$-keto sulfones and their regiospecific alkylation studies. Indian Journal of Chemistry 2010; 49, Suppl B: 937-943.

5. Jeffrey MB, Anthony JR, Swati PM, Rodney AB, Duane RR, Richard WR, C. Meacham Harrell, Douglas JP, Wei L,
Kathy LM, Chunze L, Thomayant P, Christopher JW, John JR, Kenneth SK, George DH and Paul JC. Proline bisamides as potent dual orexin receptor antagonists. Bioorganic and medicinal letters 2008;18: 1425-1430.

6. Canan K, Gulgun A-K, Suheyla O, F. BetulKaynak, Melek $\mathrm{K}$, Tulay $\mathrm{C}$ and Benay C. Synthesis and antioxidant properties of novel N-methyl-1,3,4-thiadiazol-2-amine and 4-methyl-2H-1,2,4-triazole-3(4H)-thione derivatives of benzimidazole class. Bioorganic and Medicinal Chemistry 2008; 16: 4294-4303.

7. Marijana H, Gordana P, Marko M, Marijeta K, andGrace KZ. Benzimidazole derivatives related to 2,3-acrylonitriles, benzimidazo[1,2-a]quinolines and fluorenes: Synthesis, antitumor evaluation in vitro and crystal structure determination.European Journal of Medicinal Chemistry 2010; 45: 2405-2417.

8. Fabian Lo'pez-V, Jose' Luis MF, Alicia H-C, Sergio R-M, Lilia'nYe'pez, Roberto C and Rafael C. Molecular modeling of some 1H-benzimidazole derivatives with biological activity against Entamoeba histolytica: A comparative molecular field analysis study. Bioorganic \& Medicinal Chemistry 2007; 15: 1117-1126.

9. Suresh AJ, AnithaK, Vinod, D. Design, Synthesis, Characterization and Screening of Thiophene Derivatives For Anti-Inflammatory Activity. Journal of Chemical, Biological and Physical Sciences 2011; 1Suppl 2: 304-314.

10. Thakurdesai PA,Wadodkar SG and Chopade CT. Synthesis And Anti-Inflammatory Activity of Some Benzimidazole-2Carboxylic Acids. Pharmacologyonline 2007; 1: 314-329.

11. Babu, GS, Rajani N, Malathy PS, Srinivas B, Kulandaivelu, $\mathrm{U}$ and Rao JV. Synthesis, Characterization and Evaluation of Novel N-(1HBenzimidazol-2-Yl)-2-IsatinylideneHydrazinecarboxamide Derivatives as Anti-Inflammatory Agents. Scholars Research Library 2010; 2Suppl 3: 196204.

12. Achar KCS, Hosamani KM and Seetharamareddy HR. Invivo analgesic and anti-inflammatory activities of newly synthesized benzimidazole derivatives. Eur. J. Med. Chem 2010; 45: 2048-2054.

13. Gaba M, Singh D, Singh S, Sharma V and Gaba $P$. Synthesis and pharmacological evaluation of novel 5substituted-1-(phenylsulfonyl)-2-methylbenzimidazole derivatives as anti-inflammatory and analgesic agents. Eur. J. Med. Chem 2010; 45: 2245-2249.

14. Mariappan G, Bhuyan NR, Kumar P, Kumar D and Murali $\mathrm{K}$. Synthesis and biological evaluation of Mannich bases of benzimidazole derivatives.Indian J. Chem 2011; 50Suppl B: 1216-1219.

15. Jesudason EP, Sridhar SK, Mala EJP, Shanmugapandiyan P, Inayathullah M, Arul V, Selvaraj D and Jayakumar R. Synthesis, pharmacological screening, quantum chemical and in-vitro permeability studies of N-Mannich bases of benzimidazoles through bovine cornea. Eur. J. Med. Chem 2009; 44: 2307-2312.

16. Shanmugapandiyan P,Denshing KS, Ilavarasan R, Anbalagan N and Nirmal R. Synthesis and biological activity of 2-(thiazolidin-4-one) phenyl]-1HPhenylbenzimidazoles and 2-[4-(azetidin-2-one)-3-chloro-4phenyl] -1H-Phenyl benzimidazoles. Int. J. Pharm. Sci. Drug Res. 2010; 2, Suppl 2: 115-119.

17. Reddy BA. Synthesis, Characterization and Biological Evaluation of 1,2- disubstitutedbenzimidazole derivatives using Mannich Bases. E-J. Chem 2010;7, Suppl 1: 222-226.

18. Leonard JT, Jeyaseeli L, Rajesh OS, Murugesh K, Shivakumar R and Gunasekaran V. Synthesis, antiinflammatory and antibacterial activities of 4-substituted phenyl benzimidazoles. Asian J. Chem 2006; 18: 11041108 . 
19. Gaud VM, Sreenivasulu N, Rao AS, Chigiri S. Synthesis, antimicrobial and pharmacological evaluation of substituted novel benzimidazoles. Der Pharma Chemica 2011; 3Suppl 1: 446-452.

20. Sondhi SM, Rajvanshi S, Johar M, Bharti N, Azam A and Singh AK. Anti-inflammatory, analgesic, and antiamoebic activity evaluation of pyrimido[1,6a]benzimidazole derivatives synthesized by the reaction of ketoisothiocyanates with mono and diamines. Eur. J. Med. Chem 2002; 37: 835-843.

21. Mohamed BG, Abdel-Alim M and Hussein MA. Synthesis of 1-acyl-2-alkylthio-1,2,4-triazolobenzimidazoles with antifungal, anti-inflammatory and analgesic effects. Acta Pharm 2006; 56: 31-48.

22. Kaplancikli ZA, Turan-Zitouni G, Ozdemir A, Can Ozgur D and Chevallet P. Synthesis andAntinociceptive Activities of Some Pyrazoline Derivatives. European Journal of Medicinal Chemistry 2009; 44: 2606-2610.

23. Shukla A.Synthesis and Biological Screening of Benzimidazole Derivatives. International Journal of Pharmaceutical sciences and Research 2012; 3Suppl, 3: $922-$ 927.

24. Singh P and Jangra PK.Oxadiazoles: A novel class of anticonvulsant agents. Pelagia Research Library 2010; 1Suppl 3: 118-123.

25. Shahayar M, Majumdar A, Salahuddin, Garg R and Pandey RD. Synthesis, Characterization And Pharmacological Screening of Novel Benzimidazole Derivatives. Arabian Journal of Chemistry 2011; 1-6.

26. Bhrigu B, Siddiqui N, Pathak D, Alam SM, Ali R and Azad B. Anticonvulsant Evaluation of Some Newer Benzimidazole Derivatives: Design And Synthesis. ActaPoloniaePharmaceutica 2012; 69Suppl 1: 53-62.
27. Anandarajagopal K, Tiwari Ravi N, Bothara KG, J.AnbuJeba, Dineshkumar C and Promwichit P. 2Mercaptobenzimidazole Derivatives: Synthesis and Anticonvulsant Activity. Pelagia Research Library 2010; 1Suppl 2: 132-138.

28. Patil A, Ganguli S and Surana S. Synthesis And Antiulcer Activity Of 2-[5-Substituted-1-H-Benzo(D)Imidazole-2-Y1 Sulfinyl] Methyl-3-Substituted Quinqzoline-4-(3H)Ones. Journal of Chemical Sciences 2010; 122Suppl 3: 443-449.

29. Khan F and Nadeem S. Anti-ulcerogenic effect of 2(pyrimidinylsulfinyl) benzimidazole derivative against different ulcerogenic agents in rats.Pharmacology onlinenewsletter 2011;2: 1217-1222.

30. Thakare PB and Ansari AJ. Synthesis and Antiulcer, Anti Secretory Activity of Some New Substituted 2(Pyrimidinylsulfinyl) Benzimidazole derivatives International Journal of Research In Pharmaceutical And Biomedical Sciences 2011; 2Suppl 2: 695-700.

31. Shin JM, Sache G, Cho YM and Garst M. 1-Arylsulfonyl-2(Pyridylmethylsulfinyl) BenzimidazoleAs New Proton Pump Inhibitor Prodrugs. Molecules 2009; 14: 5247-5280.

32. Shah K, Chhabra S, Shrivastava SK and Mishra P. Benzimidazole: A promising Pharmacophore. Medicinal Chemistry Research 2013; 22 Suppl 11; 5077-5104.

33. Santosh PC, Pandeya SN, Pathak AK. Benzimidazole: A versatile chemical entity. Int. J. Res. Ayurveda Pharm. 2011; 2 (6): 1126-1137.

\section{Cite this article as:}

Rituparna Palit, Rajesh Kumar, Nikita Saraswat, Ankita Wal, Prabhat Kumar Upadhyaya. Benzimidazole: An overview. Int. J. Res. Ayurveda Pharm. Nov - Dec 2016;7(6):68-73 http://dx.doi.org/10.7897/2277-4343.076243 every effort has been taken to verify the accuracy of the content published in our Journal. IJRAP cannot accept any responsibility or liability for the site content and articles published. The views expressed in articles by our contributing authors are not necessarily those of IJRAP editor or editorial board members. 